\title{
Lyophilisate and Solvent for Suspension for Injection Dosage Form
}

National Cancer Institute

\section{Source}

National Cancer Institute. Lyophilisate and Solvent for Suspension for Injection Dosage

Form. NCI Thesaurus. Code C149635.

Sterile lyophilisate and sterile solvent intended for the preparation of a suspension for injection, for veterinary use, by dispersing the lyophilisate in the solvent. 